\title{
Pengaruh Model Pembelajaran Role Playing Terhadap Hasil Belajar Bahasa Indonesia Siswa SDN Asemrowo II
}

\author{
Dwi Setyowati ${ }^{1}$, Erlin Kartikasari ${ }^{2}$, Endang Nuryasana ${ }^{3}$ \\ PGSD, FBS, Universitas Wijaya Kusuma Surabaya \\ email: setyowatidwi04@gmail.com¹, erlinkartikasari@uwks.ac.id², \\ endangnur_fbs@uwks.ac.id ${ }^{3}$
}

\begin{abstract}
The purpose of this study was to determine the effect of role playing learning models on student learning outcomes in Indonesian 8 Theme areas where I live in fiction stories grade 4 SDN Asemrowo II Surabaya. This research using is quantitative research using quasi experimental research designs. The sample used in this study is nonprability sampling with saturated sampling so that all student used as sample, all classes 4 consisting classes $A$ and $B$. Class $A$ was chosen as the control class dan class $B$ was chosen as the experimental class, each class containing 25 student. The research instrument used was a test (pretest and posttest). The result of data analysis obtained from the independent $t$ test are sig ( 2 tailed $=0,000)<a 0$, 05) it means that Ho is rejected dan Ha is accepted, Role Playing learing model influences student learning outcomes.
\end{abstract}

Keywords : learning model, learning outcomes, role playing.

\begin{abstract}
Abstrak
Penelitian ini memiliki tujuan untuk mendeskripsikan pengaruh dalam menggunakan model pembelajaran role playing terhadap hasil belajar siswa pada mata pelajaran Bahasa Indonesia tema 8 materi cerita fiksi kelas IV Sekolah Dasar Negeri Asemrowo II Surabaya. Penelitian ini menggunakan metode kuantitatif dengan menggunakan desain penelitian eksperimen semu (Quasi Experimental). Sampel yang digunakan adalah nonprability sampling dengan sampling jenuh sehingga semua anggota populasi digunakan sebagai sampel, yaitu seluruh kelas IV yang terdiri atas kelas A dan B. Kelas A ditunjuk sebagai kelas kontrol dan kelas B sebagai kelas eksperimen, setiap kelas berisi 25 siswa. Instrumen yang dipilih pada penelitian ialah lembar tes (Pretest- posttest) serta dokumentasi berfungsi untuk memperkuat data. Hasil analisis data yang didapat dari uji Independent $T$ Test adalah nilai signifikasi $(2$ tailed $=0,000)<\mathrm{a} 0,05)$ dengan artian Ho ditolak dan $\mathrm{Ha}$ diterima, sehingga model pembelajaran role playing berpengaruh terhadap hasil belajar siswa.
\end{abstract}

Kata Kunci : model pembelajaran, hasil belajar, role playing. 


\section{PENDAHULUAN}

Pendidikan Bahasa Indonesia merupakan bagian dari sistem pendidikan di Indonesia yang wajib dipelajari oleh siswa Sekolah Dasar. Bahasa utama bangsa Indonesia adalah Bahasa Indonesia, dengan itu setiap individu dapat berkomunikasi meskipun daerah tempat tinggal mereka tidak sama. Sebab itu, perlu untuk setiap manusia mendapatkan pendidikan Bahasa Indonesia sejak dini. Saat menempuh pendidikan di sekolah, pelajaran Bahasa Indonesia wajib ditempuh oleh siswa mulai tingkat Sekolah Dasar sampai dengan perkuliahan dengan tujuan agar siswa dapat mengembangkan skill berkomunikasi. Pembelajaran Bahasa Indonesia mempunyai nilai keterampilan, berbicara (bercakap), menyimak, menulis, dan membaca. Sebab itu, siswa diharap dapat menguasai empat kemampuan tersebut. Meskipun mata pelajaran Bahasa Indonesia wajib diikuti. Namun, tidak sedikit siswa SD yang malas mempelajarainya khususnya pada materi yang memiliki bacaan yang panjang, hal tersebut dikarenakan pembelajaran yang diajarkan dikemas secara konvensional.

Pembelajaran secara

konvensional yang dimaksud adalah pembelajaran dengan menggunakan metode ceramah pada semua kegiatan pembelajaran dari awal sampai akhir pertemuan tanpa dipadukan dengan model pembelajaran yang lain. Hal tersebut akan membuat siswa merasa bosan dan tidak antusias dalam mengikuti pembelajaran Bahasa Indonesia, meskipun metode ceramah juga dibutuhkan disetiap pembelajaran. Maka dari itu metode ceramah perlu dimodifikasi atau dipadukan dengan model pembelajaran yang lain agar siswa lebih antusias dan mudah memahami materi yang dijelaskan oleh guru.

Trianto (dalam Afandi dkk, 2013:15) mengatakan jika model pembelajaran ialah rancangan atau bentuk yang dijadikan sebagai acuan dalam merencanakan kegiatan belajar. Kegiatan belajar mengajar di kelas dapat terealisasi melalui penerapan pendekatan dari model pembelajaran yang sesuai, meskupun pembelajaran berpusat pada siswa. Arends (dalam Hayati, 2017:10) menjelaskan model pembelajaran ialah bentuk tindakan antara siswa, pendidik, dan bahan ajar yang mencakup 1) strategi, 2) metode, 3) teknik, dan 4) pendekatan pembelajaran. Soekamto dkk, (dalam Trianto, 2010:74) menjelaskan model pembelajaran ialah suatu rangka yang tersusun secara terperinci dan sistematis untuk mencapai apa yang diinginkan.

Berdasarkan beberapa pendapat para ahli yang telah disampaikan maka dapat diambil simpulan, model pembelajaran adalah aturan pembelajaran yang dilaksanakan secara teratur yang didalamnya mencakup strategi, metode, teknik, dan pendekatan pembelajaran.

Kartikasari (2016) pernah menerapkan model pembelajaran yang tepat dan dapat menjadi daya 
tarik siswa untuk meningkatkan keterampilan berbicara Bahasa Indonesia untuk penutur asing di Surabaya European School Indonesia dengan menerapkan model pembelajaran Raja Darmawan nilai peserta didik meningkat dibandingkan dengan yang diajar dengan metode yang biasa atau konvensional. Penentuan model pembelajaran yang tepat penting untuk menarik minat siswa belajar Bahasa Indonesia.

Model pembelajaran yang akan digunakan oleh peneliti untuk menarik siswa agar siswa giat dan bersemangat saat mengikuti pembelajaran dan mudah memahami materi adalah model pembejaran role playing. Model pembelajaran role playing di Negara Indonesia lebih dikenal dengan sebutan bermain peran atau drama. Pembelajaran Abdullah (2016 : 2) mengatakan "Role Play is a learning model as a part of the simulation are directed to creativity historical event, creativity actual event, event that may arise in the future or role playing emphasizes the role of the leaners in a game or an event. Trought this role play, student can experience other situation trough role play, so that students will have the experience of identity of the character of those who played".

Ahmadi (dalam Basri 2017:41) menjelaskan bahwa role playing ialah cara dalam menguasai bahan belajar melewati pengembangan berfikir dan pendalaman kondisi yang dilakukan oleh peserta didik dengan cara memperagakan makhluk hidup maupun tidak. Djamarah (dalam Tarigan, 2016:104) mengatakan bahwa model pembelajaran role playing diartikan sebagai sosiodrama yang pada dasarnya membuat sebuah keadaan serupa dengan drama dan disajikan didepan kelas. Supriono (dalam Sha'adah dkk, 2013:30) menjelaskan bahwa role playing adalah menghidupkan kembali cerita di masa lalu, kejadian yang nantinya akan datang di masa depan, peristiwa sekarang, pada waktu, dan tempat tertentu. Berdasarkan pendapat para ahli yang telah dijelaskan maka dapat ditarik simpulan bahwa model pembelajaran role playing adalah aktivitas belajar mengajar yang diterapkan untuk mencapai tujuan pendidikan dan didalamnya terdapat bagian simulasi yang diarahkan untuk mengkreasikan suatu kejadian sehingga peserta didik dapat mengungkapkan apa yang dirasakannya.

Pembelajaran bahasa Indonesia materi cerita fiksi yang terdapat pada tema 8 jika dipadukan dengan model pembelajaran role playing sangat cocok karena nantinya siswa bisa menyimulasikan atau memerankan peristiwa yang terdapat pada bacaan cerita fiksi, meskipun bacaan cerita fiksi cukup panjang namun peserta didik tidak akan merasa bosan saat mengikuti pembelajaran berlangsung dan terbantu dalam memahami isi bacaan cerita fiksi. Siswa juga dapat mengungkapkan apa yang difikirkannya melalui peran yang di bawakan, role playing juga bisa 
melatih siswa terbiasa dalam berbicara dan bekerja sama dengan teman sebayanya, dengan begitu pembelajaran tidak berpusat pada guru dan hasil yang diinginkan tercapai.

Model pembelajaran role playing yang diharapkan dapat menjadi solusi masalah pembelajaran dan tidak menutup kemungkinan apabila memiliki kelemahan dan kelebihan :

\section{Kelebihan Role Playing}

Djamarah (dalam Tarigan, 2016:104) menyebutkan bahwa Role Playing memiiliki beberapa kelebihan yaitu :

1) peserta didik dapat mengembangkan fikirannya dalam hal memahami, mengingat dan mensimulasikan isi cerita yang nantinya akan tampilkan;

2) peserta didik diajak untuk berlatih kreatif dan berinisiatif;

3) peserta didik akan berlatih percaya diri ketika melakukan bermain peran;

4) bakat yang dimiliki oleh peserta didik dapat dikembangkan sehingga nantinya akan tumbuh jiwa seni drama dalam dirinya;

5) peserta didik dapat berlatih untuk membagi tugas dengan kelompoknya;

6) seluruh peserta didik yang didalam kelas dapat berbartisipasi saat pembelajaran;

7) model pembelajaran role playing dapat mewujudkan kelas yang aktif, kreatif, disenangi banyak siswa dan tidak membosankan;
8) peserta didik lebih bersemangat dalam mengikuti proses belajar mengajar;

9) model pembelajaran role playing akan membuat pesera didik berkesan dan melekat di ingatan;

10) melatih kerja sama dengan semama teman untuk dapat menampilkan yang terbaik.

Berdasarkan kelebihan dari model pembelajaran role playing yang telah dipaparkan, diharapkan dapat membantu guru dalam mempermudah mencapai tujuan pembelajaran.

\section{Kelemahan Role Playing}

Role Playing juga memiliki beberapa kelemahan. Kurniasih dan Sani (dalam Afifi, 2017:33) mengatakan bahwa ada beberapa kekurangan atau kelemahan Role Playing :

1) membutuhkan durasi waktu yang tidak sedikit;

2) membutuhkan kerjasama dari pendidik maupun peserta didik;

3) banyak peserta didik memiliki perasaan malu saat memperagakan peran dalam peristiwa atau cerita;

4) hanya beberapa materi yang dapat diterapkan dalam model pembelajaran ini;

5) memerlukan ruang kelas yang cukup luas.

Perlu adanya upaya dalam mengatasi role playing supaya tujuan pembelajaran yang diharapkan tercapai sesuai dengan semestinya. 


\section{Cara Mengatasi Kelemahan Role Playing}

Berikut cara mengatasi

kelemahan role playing antara lain:

1) guru menjelasan kepada peserta didik dengan memperkenalkan model pembelajaran role playing;

2) memberikan naskah sederhana untuk bermain peran agar siswa mudah memahami cerita;

3) memberikan penjelasan bagaimana proses pelaksaan bermain peran;

4) memberikan contoh sebelum melaksanakan bermain peran;

5) menata kelas agar siswa dapat bermain peran dengan leluasa meskipun tidak maksimal;

6) memberikan batasan waktu setiap kelompok yang akan tampil;

7) memberikan reward setelah siswa bermain peran agar siswa bersemangat untuk menyelesaikannya.

Dari beberapa cara untuk mengatasi kelemahan Role Playing telah dijelaskan, penulis berharap cara tersebut dapat meminimalisir kelemahan yang ada agar pembelajaran yang terjadi didalam kelas dan dapat membantu tercapainya tujuan pembelajaran.

Tahapan atau Langkah Role Playing

Tujuan pembelajaran dapat tercapai jika guru memperhatikan tahapan atau langkah-langkah pembelajaran role playing. Suyatno (dalam Ariwitari dkk, 2014:105) mengatakan terdapat tahapan atau langkah role playing :
1) guru menerangkan kepada siswa mengenai materi jenis-jenis cerita fiksi dan unsur-unsurnya;

2) guru memberikan satu cerita yang dikemas dalam bentuk skenario atau teks dialog yang digunakan untuk role playing;

3) guru melakukan pembagian kelompok atau anggota;

4) guru menugaskan siswa untuk membagi peran yang ada didalam teks dialog tersebut;

5) guru menjelaskan peraturan role playing;

6) guru memberikan contoh bermain peran berdasarkan skenario yang ada;

7) guru mempersilahkan siswa untuk berlatih dan memahami isi cerita yang diperankan;

8) guru memanggil perkelompok secara acak untuk bermain peran berdasarkan cerita yang telah ditentukan;

9) Guru memberikan pujian dan reward untuk kelompok yang telah menunjukkan penampilannya.

Sesuai dengan penjelasan langkah-langkah atau tahapan Role Playing diharapkan dapat membantu proses pembelajaran yang berlangsung di kelas.

Hasil belajar atau nilai siswa diharapkan pada penelitian ini adalah perubahan nilai yang dipengaruhi model pembelajaran role playing. Makmun (dalam Husamah dkk, 2016:9) menjelaskan hasil belajar adalah hasil yang ditunjukkan dengan nilai tes yang diberikan guru, lima jenis hasil belajar yang nantinya akan 
diperoleh siswa yaitu 1) informasi verbal atau lisan; 2) keterampilan Intelektual atau berfikir; 3) strategi kognitif atau pengetahuan; dan 4) sikap, sedangkan Sudjana (dalam Yanto, 2015:57) mengatakan jika hasil belajar ialah kemampuan yang dimiliki siswa dalam bentuk perubahan yang dilihat sesudah menerima pengalaman belajar, bukan hanya perubahan dalam bentuk pengetahuan atau pemikiran, akan tetapi pengetahuan dalam membentuk tingkah laku. Nuryasana (2019:75) mengatakan hasil belajar yaitu gambaran mengenai apa yang semestinya dikembangkan, dikerjakan, dan dipahami siswa yang dapat diukur dengan menggunakan beberapa model penilaian. Berdasarkan pendapat beberapa ahli dapat diambil simpulkan, hasil belajar ialah sesuatu yang didapat dari tindakan belajar yang terkadang ditentukan dengan nilai tes yang diberikan guru untuk siswa dan dapat berupa perubahan afektif, kognitif, dan psikomotor.

Seperti yang dikatakan, belajar ialah proses yang mengakibatkan perubahan baik perilaku maupun pengetahuan. Keberhasilan dalam belajar dapat ditinjau dari beberapa macam faktor. Maimunah (2014:153) mengatakan bahwa ada beberapa hal yang dapat mempengaruhi faktor hasil belajar yaitu :

a. Faktor Individual

Faktor yang ditemukan dalam diri seseorang, salah satu faktor individual tersebut ialah pertumbuhan, kecerdasan, kesadaran diri sendiri dan dorongan untuk melakukan sesuatu.

b. Faktor Sosial

Faktor yang terlihat pada luar diri seseorang, salah satu faktor sosial adalah keluarga, cara guru mengajar, perangkat yang digunakan dalam pembalajaran, lingkungan, dorongan motivasi sosial.

\section{Kerangka Penelitian}

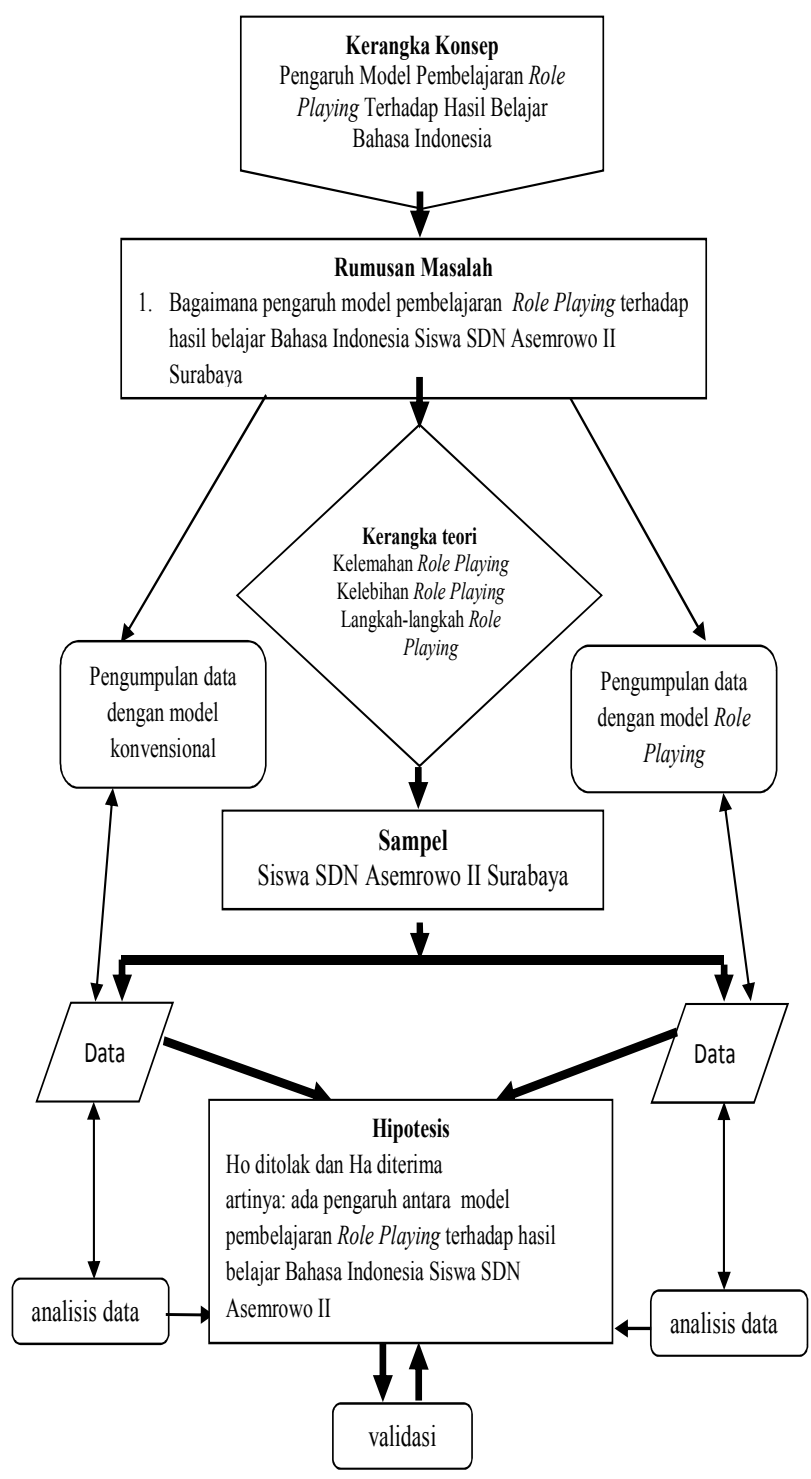

Gambar 1. Kerangka berpikir 


\section{METODE PENELITIAN}

Penelitian ini dilaksanakan di SDN Asemrowo II Surabaya yang beralamat di Jl. Dupak Rukun (Pasar Loak) Kecamatan Asemrowo Kelurahan Asemrowo. Desain penelitian yang digunakan adalah eksperimen semu (Quasi Experimental).

Tabel 1. Desain Penelitian

\begin{tabular}{|c|c|c|c|}
\hline Kelas & Pretest & $\begin{array}{c}\text { Treat } \\
\text { ment }\end{array}$ & Posttest \\
\hline Kontrol & $\mathrm{O} 3$ & $\mathrm{O} 2$ \\
\hline $\begin{array}{c}\text { Eksperi } \\
\text { men }\end{array}$ & $\mathrm{O} 1$ & $\mathrm{X}$ & $\mathrm{O} 4$ \\
\hline
\end{tabular}

keterangan :

$\mathrm{X}$ : penggunaan role playing sebagai perlakuan.

O1 : pemberian pretest di kelas eksperimen sebelum diberikan perlakukan.

O2 : pemberian posttest di kelas eksperimen setelah diberikan perlakuan.

O3 : pemberian pretest di kelas kontrol sebelum diberikan materi

O4 : pemberian posttest di kelas eksperimen sesudah diberikan materi.

Siswa kelas IV di SDN Asemrowo II Surabaya tahun ajaran 2020 dijadikan sebagai populasi penelitian. Sampel yang digunakan yaitu nonprability sampling dengan sampling jenuh sehingga semua siswa IV A dan B dijadikan sampel. Kelas
A ditunjuk menjadi kelas kontrol dan B kelas eksperimen (terdapat treatment), satu kelas berisi 25 siswa. Instrumen yang digunakan adalah lembar tes yaitu pretestposttest serta dokumentasi. Lembar tes yang digunakan pada pretest (sebelum pembelajaran) dan posttest (sesudah pembelajaran) berbentuk essai atau uraian. Lembar pretest (sebelum pembelajaran) dijadikan sebagai alat untuk mengukur pemahaman awal siswa. lembar posttest (sesudah pembelajaran) dijadikan sebagai alat ukur kemampuan siswa. Soal yang terdapat pada lembar pretest (sebelum pembelajaran) dan posttest (sesudah pembelajaran) berbeda namun tetap dalam indikator yang sama. Jumlah soal pada pretest dan posttest masingmasing tujuh soal. Lembar tes divalidasi oleh tim ahli yang sesuai dengan bidangnya. Setelah tes tersebut dinyatakan valid maka lembar tes dapat diberikan pada siswa dikelas kontrol maupun eksperimen. Dokumentasi disertakan dengan tujuan memperkuat data yang sudah didapatkan yang berupa nilai hasil pretest-posttest serta pelaksaan pembelajaran dikelas eksperimen dan kontrol. Teknik pengambilan data dilakukan dengan cara membuat kisikisi soal, membuat soal pretestposttest, membagikan ke kelas eksperimen dan kontrol serta menilai hasil belajar siswa.

Materi yang disampaikan di kelas eksperimen dan kontrol sama yaitu mengenai cerita fiksi. Pelaksanaan penelitian meliputi 
kegiatan pretest, proses pembelajaran dan posttest. Deskripsi pelaksanaan penelitian dapat dijabarkan sebagai berikut :

a. Pemberian soal pretest

Pretest diberikan untuk mengukur pemahaman awal siswa kelas ekperimen dan kontrol, sebelum diberikan materi mengenai cerita fiksi siswa dimita untuk mengerjakan soal pretest (sebelum pembelajaran). Sebelum siswa mengerjakan soal pretest, siswa di informasikan bahwa mereka akan belajar materi cerita fiksi.

b. Proses Pembelajaran

Untuk proses pembelajaran yang pertama dilaksanakan di kelas kontrol (IVA). Pembelajaran dikelas kontrol menggunakan metode tanya jawab dan ceramah. Siswa diminta untuk mendengarkan penjelasan yang diterangkan oleh guru tentang materi cerita fiksi. Terkadang guru mengajak siswa untuk tanya jawab, namun tidak sedikit yang kurang antusias dalam pembelajaran. Ketika guru menerangkan materi cerita fiksi tidak sedikit siswa yang menghiraukan dan berbincang dengan rekan sebangkunya. Proses pembelajaran kedua dilakukan di kelas eksperimen (IVB), saat pembelajaran di kelas eksperimen guru memberikan perlakukan supaya siswa giat dan bersemangat dalam menjalankan proses pembelajaran dikelas. Perlakuan

yang diberikan ialah model pembelajaran role playing yang dirasa mampu membangkitkan semangat siswa dan mudah mencerna materi yang akan diajarkan.

c. Pemberian Posttest

Posttest diberikan ketika siswa kelas eksperimen dan kelas kontrol telah mendapatkan materi. Posttest diberikan untuk mengetahui hasil atau nilai belajar siswa mengenai materi cerita fiksi. Nilai yang telah terkumpul akan diolah.

Untuk dapat menarik simpulan dalam penelitian, diperlukan pengolahan data terlebih dahulu, dalam pengolahan data kuantitatif dapat menggunakan aplikasi SPSS versi 23. Adapun uji yang dilakukan sebelum mengetahui kebenaran hipotesis yaitu :

a. Uji Prasyarat

Langkah awal adalah analisis data untuk menguji hipotesis, diperlukan uji prasyarat dengan mempergunakan aplikasi SPSS versi 23.

1) Uji Normalitas

Tujuan melakukan uji
normalitas adalah untuk
membuktikan apakah data pretest-
posttest kelas eksperimen dan
kontrol berdistribusi normal atau
tidak (sebaran sebuah data). Uji ini
menggunakan cara uji
Kolmogorov-Smirnov dan berikut
ketentuannya :
data dikatakan berdistribusi normal
apabila nilai Signifikansi $>0,05$.


data dikatakan tidak berdistribusi normal apabila nilai Signifikansi $<$ 0.05 .

2) Uji Homogenitas

Uji homogenitas termasuk langkah selanjutnya yang digunakan agar penulis dapat membuktikan apakah varian kelas eksperimen dan kontrol terdapat kesamaan, sesuai dengan pengambilan keputusan antara lain :

data dikatakan homogen apabila nilai Signifikansi $>0,05$

data tidak dikatakan homogen apabila nilai Signifikansi $<0,05$

b. Uji Hipotesis

Dengan

melakukan pengujian hipotesis penulis dapat mengetahui kebenaran suatu hipotesis dan menarik simpulan apakah hipotesis pada penelitian ditolak atau diterima. Peneliti memilih mempergunakan uji Independent $T$ Test yang bertujuan agar dapat menguji nilai signifikansi atau perbedaan ratarata dua kelompok yang saling bebas dengan menggunakan aplikasi SPSS versi 23 yang memiliki ketentuan :

$\mathrm{Ha}$ ditolak dan Ho diterima, apabila Signifikansi (2-tailed) > 0,05

$\mathrm{Ha}$ diterima dan Ho ditolak, apabila Signifikansi (2-tailed) < 0,05

\section{HASIL DAN PEMBAHASAN}

Sesuai dengan nilai tes yang sudah diperoleh, berikut rata-rata nilai yang didapatkan siswa yaitu :

Tabel 2. Nilai rata-rata kelas eksperimen dan kontrol

\begin{tabular}{|c|c|c|}
\hline Kelas & $\begin{array}{c}\text { Nilai } \\
\text { Pretest }\end{array}$ & $\begin{array}{c}\text { Nilai } \\
\text { Posttest }\end{array}$ \\
\hline $\begin{array}{c}\text { Kontrol } \\
\text { (IV A) }\end{array}$ & 35,84 & 60,60 \\
\hline $\begin{array}{c}\text { Eksperimen } \\
\text { (IV B) }\end{array}$ & 41,8 & 81,2 \\
\hline
\end{tabular}

Apabila dilihat dari tabel yang disajikan bisa dipastikan ada ketidaksamaan rata-rata nilai kelas eksperimen dan kontrol. Rata-rata yang didapat belum cukup untuk membuktikan kebenaran hipotestis penelitian. oleh karena itu, hasil yang didapatkan dari pretest-posttest kelas eksperimen maupun kelas kontrol akan diolah melalui beberapa tahapan dengan bantuan aplikasi SPSS versi 23

a. Uji Prasyarat

Sebelum dilaksanakannya uji hipotesis alangkah baiknya jika melaksankan uji normalitas dan homegenitas terlebih dahulu dengan bantuan aplikasi SPSS versi 23.

1) Uji Normalitas

Uji normalitas peneliti menggunakan uji kolmogorovsmirnov : 
Tabel 3. Nilai uji normalitas

kelas kontrol dan eksperimen

\begin{tabular}{|c|c|c|}
\hline Kelas & $\begin{array}{c}\text { Kolmogorov- } \\
\text { semirnov } \\
\text { (sig.) }\end{array}$ & $\begin{array}{c}\text { Shapiro- } \\
\text { wilk } \\
\text { (sig.) }\end{array}$ \\
\hline $\begin{array}{c}\text { Pretest } \\
\text { eksperimen }\end{array}$ & 0.200 & 0.125 \\
\hline $\begin{array}{c}\text { Posstest } \\
\text { eksperimen }\end{array}$ & 0.177 & 0.502 \\
\hline $\begin{array}{c}\text { Pretest } \\
\text { Kontrol }\end{array}$ & 0.074 & 0.259 \\
\hline $\begin{array}{c}\text { Posttest } \\
\text { Kontrol }\end{array}$ & 0.200 & 0.497 \\
\hline
\end{tabular}

Sesuai dengan hasil data yang telah dioleh dengan menggunakan aplikasi SPSS versi 23 dapat dilihat jika data yang diperoleh mendapatkan nilai siginifikansi $>0.05$ dengan itu data berdistribusi normal.

2) Uji Homogenitas

Uji homogenitas bertujuan untuk mengetahui kesamaan varian populasi kelas kontrol dan ekperimen diperlukan Uji Homogenitas terlebih dahulu, hasil yang diperoleh dari aplikasi SPSS versi 23. Uji homogenitas pada penelitian ini menggunakana cara One Way Anova. Berikut sajian data yang telah diperoleh :
Tabel 4. Data hasil uji homogenitas

Test of Homogeneity of Variances

Hasil belajar siswa

\begin{tabular}{|r|r|r|r|}
\hline $\begin{array}{r}\text { Levene } \\
\text { Statistic }\end{array}$ & df1 & df2 & Sig. \\
\hline 2.126 & 1 & 48 & .151 \\
\hline
\end{tabular}

Berdasarkan dari tabel yang telah disajikan diperoleh nilai signifikansi $0.151>0,05$ dengan itu data memunyai varian yang homogen.

b. Uji Hipotesis

Tahap akhir yaitu, melakukan uji hipotesis agar dapat membuktikan kebenaran suatu hipotesis dan menarik simpulan apakah hipotesis penelitian diterima atau tidak. Pada tahap ini penulis memilih uji Independent $T$ Test karena kita akan menguji perbedaan rata-rata dua kelompok yang saling bebas.

Ho : Tidak ada pengaruh antara model pembelajaran role playing terhadap hasil belajar siswa pada pelajaran Bahasa Indonesia materi cerita fiksi.

$\mathrm{Ha}$ : Ada pengaruh antara model pembelajaran role playing terhadap hasil pelajar siswa pada pelajaran Bahasa Indonesia ${ }_{\mathrm{i}}$ materi cerita fiksi.

Berdasakan hasil uji Independent $T$ Test yang didapatkan terlihat jika ada pengaruh hasil belajar atau nilai yang didapatkan siswa dengan 


\begin{abstract}
mempergunakan model pembelajaran role playing dibandingan jika hanya memanfaatkan metode ceramah. Hal ini dapat disesuaikan dengan pengambilan ketentuan uji Independent $T$ Test yang menyatakan Ho akan ditolak dan Ha diterima jika nilai signifikansi $(2$ tailed $=0,000)<0,05)$ sehingga model pembelajaran role playing yang digunakan saat pembejaran materi cerita fiksi berpengaruh terhadap hasil belajar siswa.
\end{abstract}

\section{SIMPULAN DAN PENUTUP}

Berdasarkan hasil dan pembahasan penelitian yang sudah dipaparkan maka dapat diambil simpulan bahwa model pembelajaran role playing (Bermain peran) berpengaruh terhadap hasil belajar siswa pada pembelajaran Bahasa Indonesia materi cerita fiksi. Hasil belajar siswa dengan menggunakan model pembelajaran role playing lebih baik dari pada hasil belajar siswa dengan menggunakan pembeajaran konvensional. Hal tersebut ditunjukan oleh data berikut :

1. Nilai rata-rata posttest pada kelas eksperimen adalah 81,2 sedangkan nilai rata-rata posttest pada kelas kontrol adalah 60,60

2. Nilai uji independent $t$ test diperoleh nilai signifikansi (2 tailed $=0,000)<0,05$ sehingga Ho ditolak dan Ha diterima.

Saran yang dapat disampaikan oleh penulis pada penelitian ini adalah :
1) keberhasilan dalam penggunaan model pembelajaran role playing bisa dijadikan referensi pendidik saat mengajar pembelajaran Bahasa Indonesia materi cerita fiksi yang terdapat pada buku tema 8 kelas IV;

2) alangkah baiknya guru memilih model pembelajaran role playing agar siswa bersemangat, tidak mengalami kebosanan dan mudah mencerna materi yang diberikan guru;

3) guru dapat memanfaatkan model pembelajaran role playing untuk meraih tujuan pembelajaran yang diharapkan;

4) bagi peneliti selanjutnya, hasil yang sudah didapat dari penelitian ini bisa dijadikan sebagai masukan, rujukan, dan perbandingan agar dijadikan penelitian lanjutan yang lebih baik.

\section{DAFTAR RUJUKAN}

Abdullah, A. 2016. Instilling Values Character Education Trough Playing Role Model in Learning History. Education and Humanities Rasearch, 84: 36-39.

Afandi, M., Chamalah, E., \& Puspita , O. (2013). Model dan Metode Pembelajaran Di Sekolah. Semarang: Unissula Press.

Afifi, F. 2017. Pengaruh Penerapan Model Role Playing Terhadap Keterampilan Berbicara Pada Pembelajaran Terpadu Di Kelas IV SD Negeri 2 
Sukoharjo II. Lampung: Universitas Negeri Lampung.

Ariwitari, R., \& Kritiantari Rini. 2014. Pengaruh Model Pembelajaran Role Playing Berbantu Media Audio Visual Terhadap Hasil Belajar PKN Kelas V SD Gugus I Tampaksiring. Jurnal Mimbar PGSD Universitas Pendidikan Ganesha, 2 (1): 1-10.

Basri, H. 2017. Penerapan Model Pembelajaran Role Playing Untuk Meningkatkan Hasil Belajar Bahasa Indonesia Siswa Kelas V SDN 032 Kualu Kecamatan Tambang. Jurnal Pendidikan, 1 (1): 3953.

Hayati, S. 2017. Belajar dan pembelajaran Berbasis Cooperative Learning. Magelang: Graha Cendekia.

Husaman, Pantiwati Y., Restian A., Sumarsono P. 2016. Belajar dan Pembelajaran. Malang: Universitas Muhammadiyah Malang.

Kartikasari, Erlin. 2016. Pengaruh Penggunaan Model Pembelajaran Raja Darmawan Terhadap Keterampilan Berbicara Bahasa Indonesia Untuk Penutur Asing (BIPA) Di Surabaya European School Indonesia. Prosiding Seminar Nasional Pendidikan

Pancasila dan Kewarganegaraan II. 28. ISBN 2460-0318
Maimunah, B. 2014. Psikologi Pendidikan. Tulungagung: IAIN Tulunggangung Press.

Nuryasana, E. 2019. Keefektifan Model Pembelajaran Think Pair Share dan Model Pembelajaran Inkuiri Terhadap Hasil Belajar IPA Siswa Kelas V SD. Trapsila : Pendidikan Dasar, 1 (1): 72-80

Sha'adah, Z., Hobri, \& Setiawan, B. T. 2013. Penerapan Metode Role Playing (Bermain Peran) Untuk Mengurangi Kesalahan Siswa Dalam Menyelesaikan Soal. Kadikma, 4 (2): 27-38.

Subekti, A. 2017. Tema 8 Daerah Tempat Tinggalku Buku Tematik Terpadu Kurikulum 2013 Kelas IV SD. Jakarta: Pusat Kurikulum dan Perbukuan, Balitbang, Kemendikbud.

Tarigan , A. 2016. Penerapan Model Pembelajaran Role Playing Untuk Meningkatkan Hasil Belajar Ips Siswa Kelas III SDN 013 Lubuk Kembang Sari Kecematan Ukui. Jurnal Primary Program Study Pendidikan Guru Sekolah Dasar Fakultas Keguruan Dan Ilmu Pendidikan Universias Riau, 5 (3): 102112.

Trianto. 2010. Mengembangkan Model Pembelajaran Tematik . Surabaya: Pretasi Belajar. 


\section{Setyowati}

Yanto, Ari. 2015. Metode Bermain Peran (Role Playing) Untuk Meningkatkan Belajar Siswa Pada Mata Pelajaran IPS. Jurnal Cakrawala Pendas. 1 (1): 53-57. 